\begin{tabular}{c} 
International Journal of Engineering \& Technology, $7(3)(2018) 1311-1319$ \\
International Journal of Engineering \& Technology \\
SPC \\
Website: $\begin{array}{c}\text { ww. sciencepubco.com/index.php/IJET } \\
\text { doi: } 10.14419 / \text { ijet.v7i3.11455 } \\
\text { Research paper }\end{array}$ \\
\hline
\end{tabular}

\title{
Review on alternative propulsion in automotives -hybrid vehicles
}

\author{
Arun B Basavaradder ${ }^{1}$, Dayananda Pai K. ${ }^{2}$, Chethan K N ${ }^{3} *$ \\ ${ }^{1}$ Post Graduate Student, Department of Aeronautical and Automobile Engineering, Manipal Institute of Technology, Manipal Academy \\ of Higher Education,Manipal-576104, Karnataka, India \\ ${ }^{2}$ Professor, Department of Aeronautical and Automobile Engineering, Manipal Institute of Technology, Manipal Academy of Higher \\ Education,Manipal-576104, Karnataka, India \\ ${ }^{3}$ Assistant Professor-Senior Scale, Department of Aeronautical and Automobile Engineering, Manipal Institute of Technology, Manipal \\ Academy of Higher Education,Manipal-576104, Karnataka, India \\ *Corresponding author E-mail: chethan.kn@manipal.edu
}

\begin{abstract}
The dynamic diminishing in overall oil stores and proximity of stringent outflows runs the world over, have made a desperate prerequisite for the making of automobiles with upgraded effectiveness. This is the change time frame to move with elective powertrains as an Electric driven, hybrid, fuel cell models are being produced. Energy Management System (EMS) are given significance for capacity and improving the effectiveness of machines. The operation of Hybrid Electric Vehicles (HEVs) in different landscape with their fuel utilization is accounted. Hybrid powertrain like series, parallel and mixed are clarified. Testing undertaking is the appropriation of charging station situation for India and compelling use of hybrid vehicles. Battery management is the key part in HEV which require search for various methodologies are taken into for creating. The correlation of the customary motors finished with hybrid vehicles.
\end{abstract}

Keywords: Degree and Architecture of Hybrid; Power Sources; Energy Storage Device and Its Management System; Charging Points.

\section{Introduction}

The considerable test confronting the vehicle division later on is to achieve ecological objectives, while in the meantime satisfying societal and private requests, for example, wellbeing, solace, and moderateness. The potential advantages of vehicles utilizing alternative powertrains, for example, fuel cell vehicles (FCEVs), hybrid electric vehicles (HEVs) or battery powered electric vehicles (BPEVs), have beforehand been surveyed from both a natural and a financial perspective. As of now the most achievable and promising answer for acquire high productivity vehicles able to fulfil both the need of the cargo part and the toxin discharges decrease is powertrain hybridization, since it can offer enhanced efficiency and low outflows, while depending on existing fuel frameworks. Specifically P-HEVs have the likelihood to travel utilizing just the electrical drive for a restricted range offering a large portion of the ecological advantages of electric vehicle (EV) operation. The Series, parallel and mixed hybrids are principle powertrains with various courses of action of engine, generator and apparatuses for driving. A Plug-In hybrid electric vehicle (PHEV) is a HV with a battery electric storage framework that can be energized by associating a fitting to an outer electric power source. EMS is essential undertaking to improve likewise the inclining applications. The operation of HEVs in off-road is inspected and simulated by utilizing sections with Matlab/Simulink. Charging focuses establishment in India is challenging.

\section{Classification of hybrid electric vehicles}

\subsection{Degree of hybrid}

\subsubsection{Mild hybrid}

Mild hybrid are for the most part of ICE outfitted with an electric machine (one motor/generator in a parallel hybrid setup) enabling the engine to be tuned off at whatever point the car is coasting, braking, or halted, yet restart rapidly. These may utilize regenerative brake and some level of energy helps to ICE, but don't have a selective electric-only mode of propulsion. Don't require a same level of battery power and don't accomplish similar levels of efficiency change when contrasted with full hybrid models, have moderate batteries and motor sizes and for the most part help speeding up from a stop and may incorporate a stop-start highlight. Not at all like full hybrid mild hybrid did not stop the engine and can't run completely on electric motor however it gives additional energy to the motors yield by a motor it is light weight, minimal effort and utilize small battery than full hybrid vehicle. This hybrid just backings help mode and regenerative braking mode. Battery measure is lower than full hybrid and it is worked just in control sustaining zone. Volvo 7900 Hybrid is a case of this kind of hybrid. The improvement of a mild hybrid powertrain framework with the combination of a normal manual transmission equipped operation and an auxiliary power output as an electric engine driving the transmission output shaft. The powertrain is a post-transmission parallel hybrid compose, using an electric machine (EM) for all time coupled to the transmission output shaft. 
This arrangement enables the EM to drive the wheels directly. There are numerous contemplations required for executing the control procedure and its integration with gear shift control. These contemplations incorporate position of clutch, gear operation, speed of engine, throttle position, and prop-shaft speed. Researches the improvement of a mild hybrid powertrain framework through the joining of an ordinary manual transmission prepared powertrain. Torque and vibration amid the gear change are overseen here. Engine particular and their breaking points for yield for productive use. Shift control systems and quality for MHEV are explained. The general execution is upgraded as needs be to the battery yield and moving. [1]. Mild hybrid are for the most part of ICE outfitted with an electric machine (one motor/generator in a parallel hybrid setup) enabling the engine to be tuned off at whatever point the car is coasting, braking, or halted, yet restart rapidly. These may utilize regenerative brake and some level of energy helps to ICE, but don't have a selective electric-only mode of propulsion. Don't require a same level of battery power and don't accomplish similar levels of efficiency change when contrasted with full hybrid models, have moderate batteries and motor sizes and for the most part help speeding up from a stop and may incorporate a stop-start highlight. Not at all like full hybrid mild hybrid did not stop the engine and can't run completely on electric motor however it gives additional energy to the motors yield by a motor it is light weight, minimal effort and utilize small battery than full hybrid vehicle. This hybrid just backings help mode and regenerative braking mode. Battery measure is lower than full hybrid and it is worked just in control sustaining zone. Volvo 7900 Hybrid is a case of this kind of hybrid.

\subsubsection{Micro hybrid}

Micro hybrids have small batteries and engines and are normally just start- stop frameworks that happen to utilize regenerative braking to charge their batteries. In truth, these truly aren't hybrid at all since "hybrid" applies to the propulsion framework, not their methods of starting and stopping the motor. They can, be that as it may, utilize their little batteries to keep up atmosphere contro while the motor is turned off... that is about the main "special" element they have over the less difficult start- stop frameworks .It's not hybrid but rather it has just a single component of hybrid the start stop engine framework which naturally stops the car engine when we are stop at signals and consequently begins car engine when we press gas pedal .This type has most reduced battery size as they just help in start stop work. Regenerative braking is there to revive the battery rapidly. Battery gives supply to auxiliary circuits to control the atmosphere

\subsubsection{Plug-in hybrid}

Plug-in electric vehicles (PHEVs) consolidate a gas or diesel engine with an electric motor and an extensive rechargeable battery Not at all like traditional half and halves, PHEVS can be connected to and revived from an outlet, enabling them to drive expanded separations utilizing just power. At the point when the battery is purged, the conventional engine turns on and the vehicle works as a traditional, non-PHEVs. These consolidate the fuel-saving advantages of hybrids with the every electric capacity of battery electric or fuel-cell vehicles. The electric motor and battery enable PHEVs to utilize less fuel and deliver less contamination than conventional cars, notwithstanding when in hybrid mode. The capability of PHEVs to work in electric and hybrid modes and their capability to helps the energy storage off the grid have made them a leader in alternative fuel vehicle advancement. A normal PHEV with an series hybrid type is basically a blend of an EV and a HEV, having the all-electric capacity of the first in city round and a littler on-board internal combustion engine (ICE) for broadened range ability as a HEV . Numerous orders for PHEVs that address the electrical framework, energy storage system (ESS), and all-electric range (AER) .Mileage of a PHEV is subject to numerous components, including how trip long, operational strategy, and the PHEVs capacity to work in electric-only mode
.PHEVs are normally ordered by their drive prepare topology, e.g., parallel, series, series- parallel, through-the-street, and power-split PHEVs. The essential distinction between a HEV and a PHEV is the larger storage pack. This bigger battery is charged by means of the electricity grid, along these lines giving the vehicle the choice of all electric working range .The Plug-in Hybrid Electric Factor (Pihef), which is a metric that consumers can without much of a stretch handle, has been displayed. The arrangement is construct absolutely with respect to the normal energy utilization of the vehicle and not on configuration condition, as most present orders [2].In this sets up advantage contrastive examination models of wind power and PHEVs under the enhancement objective of least coal utilization and toxin outflow considering multigrid associated modes. PHEVs have chargeable and dischargeable limit, which influences PHEV to can possibly be the reinforcement benefit for wind control grid connection. PHEV's deliberate grid connections can bring various advantages, for example, accomplishing vitality protection by utilizing power as rather than oil, load smoothening curve by maintaining charging and discharging conduct, also advancing wind power grid connection. PHEV's charging modes can be partitioned from two perspectives, to be specific, ordered or disordered charging, distinguish time periods, or continue charging. Thusly, its charging modes can be ordered by three sorts that takes after: the no-control charging mode, the continuous charging mode, and the charging delay mode Discharging Modes: Its affected by battery compose, limit, parameter related to it, discharge cycle, discharge loop power, and different variables [3].A dynamic model for the split PHEV and for the split hybrid framework, the vehicle ICE and electric motor is created utilizing simulation of the vehicle if actualized on a real time test system like ADVISOR (Advanced simulator) [4].PHEV powertrain produced for a light obligation conveyance vehicle, indicating conceivable changes as far as $\mathrm{CO} 2$ discharge decreases of $23 \%$ and $11 \%$, separately and contrasted result and frame dynamometer. Focused more on CV utilizing P-HEV[5].PHEVs related battery issues and their application over other sort of hybrids examined. Three distinctive energy management techniques for PHEVs (PED + HDCD + HDCS).In, which HDCS would be best for EMS. A precise re-enactment explore was performed and the three vitality EMSs were looked at [6].

\subsection{Architecture of hybrid}

The primary three Types of HEVs are parallel, series and mixed or combined HEVs. Also, there are a few sorts under every one of these classifications.

\subsubsection{Series type}

Hybrid that uses a series drivetrain just get mechanical power from the electric motor, which is controlled by either a battery or a fuel fuelled generator. These are simplest hybrid setup. In series hybrid, the electric motor is the main methods for giving energy to the wheels. The motor gets power from either the generator or battery pack keep running by an engine. An ECU decides the amount of the power originates from the battery or the motor/generator. Both do the utilization of regenerative braking recharge the battery pack. Normally engine is small in this with higher battery power which leads to expensive than parallel type.

\subsubsection{Parallel type}

In vehicles with parallel hybrid drivetrains, the engine and electric motor work pair to produce the power that drives the wheels, tend to utilize a littler battery pack rather series drivetrains, depending on regenerative braking to keep it energized. At the point when power demands are low, parallel hybrids likewise use the motor as a generator for assistant energizing, much like an alternator in regular cars. Since the motor is associated straightforwardly to the wheels in parallel drivetrains, the inefficiency of changing over mechanical energy to electricity and back is dispensed with, expanding the proficiency of these hybrids on the highway. This 
decreases, however does not take out, the efficiency advantages of having an electric engine and battery in unpredictable in stop- andgo traffic. The vehicle to display has a parallel hybrid framework, with an arrangement of two axles whose coupling torque sends energy to the front wheels. While working, proper operation modes ought to be utilized in order to meet traction torque necessities; to accomplish a high overall productivity; to keep up a sensible level of the state of charge (SOC) of the Peaking Power Source(PPS), and to recuperate braking energy however much as could be expected. For the simulation of the electric vehicle, some external and internal variables have been considered with a specific end goal to figure the battery extend [7]. The discharges from parallel HEV and genuine driving highway condition contrasting and effectiveness is examined by down weighting the vehicle, diminishing moving protection, decreasing streamlined protection, scaling back the motor. Programmed programming approval is finished. Brings about expanding in economy level of PHEV motor and brought down discharges [8]. Manages parallel HEV with a specific end goal to confront the expanding ecological contamination and decrease vitality utilization and demonstrates a modelling of electric and parallel HEV utilizing Matlab/Simulink condition which enables us to get to various parts of the vehicle, for example, motor power, sort and size of the battery or weight and to watch how changes can influence the execution and the separation voyaged. The establishment venture cost was limited and the geographic conveyance was enhanced keeping in mind the end goal to build the nature of the administration by enhancing unwavering quality[9]. Parallel hybrid vehicle expanding quickly in the car markets, the advantages out of utilizing this sort of vehicles are as yet concerned a great deal of costumers. This work researched the normal advantages, (for example, diminishing emission and expanding mileage) from utilizing the parallel HEV in contrast with the regular vehicle model of this present reality and standard driving cycles. Parallel hybrid electric vehicles which are considered in this investigation has numerous points of interest, For instance relatively lower costs cost, higher total power (since it can utilize both electric engine and ICE in the meantime if necessary) and furthermore it can fill in as a conventional vehicle. This kind of HEVs can function as conventional or can utilize the electric motor to help the primary power source, which is the internal combustion engine (ICE). Besides, the parallel HEVs still ready to find the free vitality utilizing the braking mechanism, which is the primary, favourable position of all HEVs composes. The parallel HEVs can be isolated into three principle writes micro, mild and full hybrid in light of the hybridization hardware (battery pack and electric motor/generator) sizes .The parallel HEVs can enhance efficiency up to $40 \%$ in contrast with traditional vehicle display. Be that as it may, this change relies upon the landscape types (like rising and slipping slopes), movement conditions and vehicle operations (i.e. on a highway or in a city). The outcomes endorsed that the parallel HEVs can contribute in enhancing mileage essentially on true and standard driving cycle [10].

\subsubsection{Series-parallel type}

It's the combination of series and parallel hybrid. Efficiency is higher in this comparing to the individual type. In this have highlights of both series and parallel types. There is a twofold association between the engine and the drive axle mechanical and electrical. This split power way permits interconnecting mechanical and electrical power, at some cost in complexity. Power-split gadgets are fused in the powertrain. The ability to the wheels can be either mechanical or electrical or both. This is additionally the case in parallel type. Be that as it may, the primary guideline in this framework is the decoupling of the power provided by the engine from the power required by the driver. In a normal vehicle, a bigger engine is utilized to give quickening from halt than one required for steady state cruising. This is on the grounds that a combustion engine torque is negligible at low RPMs, as the motor is its own air pump. Then again, an electric motor shows most extreme torque at slow down and is appropriate to supplement the engine torque lack at low RPMs. In this a littler, less adaptable, and efficient engine can be utilized. It is regularly a variety of the ordinary Otto cycle, for example, the Miller or Atkinson cycle. This contributes altogether to the higher performance of the vehicle, with regenerative braking assuming a significantly littler part. At bring down rates, this framework works as a series HEV, while at high speeds, where the parallel powertrain is less effective, the engine assumes control. This framework is more costly than a pure parallel framework as it needs an additional generator, a mechanical split power framework and all the more figuring energy to control the dual framework [11].

\section{Power sources}

\subsection{Engines}

\subsubsection{Gasoline}

\subsubsection{Diesel}

\subsection{Electric machines}

\subsubsection{Direct current (DC)}

There are a few favourable circumstances in keeping engine drive DC input voltage stable around its nominal value particularly with regards to limit losses. This paper manages the stability upgrade of the motor drive DC input voltage of an electric vehicle with onboard hybrid storage framework .On one hand, the characteristic voltage variety at the output battery pack can be maintained a strategic distance from by utilizing a DC/DC converter associated between the battery and the motor drive [12]. Permanent magnet (PM) motors and drives are being utilized progressively in an extensive variety of applications, have grown up. The creation of superior magnets, similar to samarium cobalt and neodymiumboron-irons, have made it conceivable to accomplish motor exhibitions that can outperform the regular DC or induction motors (IM), might be grouped into line start (which utilizes a confine to give starting torque) and inverter fed [13].In this paper, they propose an advanced brushless dc motor (BLDCM) drive for ease and high electric performance framework in electric vehicles (EV's) and hybrid electric vehicles (HEV's). Propose a progressed BLDCM drive, which can be a solid answer for ease and high performance EV and HEV propulsion framework [14]. An integral part of any advanced electric vehicle is power electronic circuits (PECs) including DC-AC inverters and DC-DC converters. A DC$\mathrm{AC}$ inverter supplies the high power electric motor and utility loads, for example, cooling framework, though a DC-DC converter supplies customary low-power, low-voltage loads A DC-DC converter in its fundamental form converts unregulated DC input voltage at a specific level to a controlled DC yield voltage at an alternate level with high conversion efficiency $(>90 \%)$. Current DC-DC converters are exchanging controllers worked at high frequencies $(10 \mathrm{kHz}-1 \mathrm{MHz})$. The extent of the segments, for example, inductors, transformers, and capacitors are drastically decreased at high frequency operation. DC-DC converters in an electric vehicle might be characterized into unidirectional and bidirectional converters, the vast majority of the DC-DC converter aimed to beat these issues to yield highly efficient, cost effective converters [15].

The motor and the generator are at the core of the vehicle drive and energy system and regularly use costly uncommon earth permanent magnet (PM) material .The key issue with magnet less and reduced magnet machines is the power density and the efficiency. The motors here are intended to work at higher speeds as a component of a central drive unit providing energy to two or four wheels. An option is to utilize smaller motors that are in-wheel or direct drive to one wheel [16]. The utilization of sliding mode control for enhancing the dynamic reaction of a self-controlled synchronous engine (SCSM) based position servo framework is displayed. Sliding mode control gives quick dynamic reaction 
with no overshoot and zero steady state error. It has the critical component of being profoundly robust, i.e., insensitive to plant parameter varieties and outer unsettling influences. The critical highlights of the sliding mode controller which make it so alluring for application in the power electronics region are 1) high precision, 2) quick reaction, 3) great stability, 4) simple design implementation and, most importantly, 5) Robustness. Low affectability to deviations in framework parameters and outer disturbance is a vital list of the controller in mechanical applications at the same time, sadly, is some of the time dismissed in the plan stage. Sliding mode control is particularly suited for frameworks where robustness is a vital performance requirement [17]. Motor for inwheel electric vehicle (EV) requires high productivity and particular torque. In perspective of this, permanent magnet brushless DC (BLDC) motor is most ordinarily utilized for this application. Be that as it may, because of the expanding expense PM, machines which don't utilize PMs are drawing in interest .Concentrated winding arrangement of action is utilized to diminish end winding volume and copper loss. This machine has high specific torque and efficiency [18]. Three basic machines DC, induction, and synchronous which served industrial needs. DC MOTOR DRIVES Control of dc machines is simple. The field mmf and the armature mmf are decoupled, as can be seen from. The torque relies upon armature current and field flux, and the field motion relies upon field current. The Induction machine is a tough, reliable, and more affordable $\mathrm{AC}$ machine. It has been the sparing workhorse for use in AC motor drive applications amid the past quarter century. It has been utilized for both low-performance and in addition superior drive applications fundamentally, there are two sorts of induction machines: the squirrel cage Induction motor (SCIM) and the wound rotor induction machine (WRIM). The SCIM is more affordable, stronger, and has been broadly utilized as a part of an extensive variety of energy ratings. It will keep on playing a prominent part in AC drive frameworks later on [19]. The stability improvement of the engine drive DC input voltage of an electric vehicle with on-board hybrid vitality stockpiling framework. A few focal points in keeping engine drive DC input voltage stable around its ostensible esteem particularly with regards to limit misfortunes and advancement of on-board vitality stockpiling or influence age frameworks with higher particular vitality execution [20].

\subsubsection{Alternating current (AC)}

The static AC motor drive portrayed in this paper uses a blend of energy and control methods which accomplish AC drive execution includes up until now not accessible. The great inherent qualities of the squirrel-cage induction motor (i.e., ruggedness, effortlessness, low-inertia rotor, minimal cost, littler size, and so forth.) make it an attractive source of mechanical power. Be that as it may, this source of mechanical power has not been completely used on customizable speed applications. From a verifiable point of view, the AC motor drive has not satisfied its potential. Every one of the points of interest, has had for quite a long time have been nullified by impediments inside the power conversion unit. Most AC power conversion units have been just movable frequency power supplies and not really universally useful drives .As of late, induction motor drives are favoured for the EV propulsion framework because of their minimal cost, high reliability, high speed properties, and assembling assistance. Simultaneously, the permanent magnet brushless dc engines (indirect driven and direct-driven) highlighting compactness, low weight, and high efficiency, have turned into an option for the EV propulsion frameworks. The last sorts of engines are likewise called wheel motors or hub-in motors, which are directly, mounted inside the wheels so the transmission gears and differentials are eliminated with related energy loss [21].

\section{Energy storage systems}

\subsection{Batteries}

Future of the battery pack clarified, arrangement of battery parts with various material and obsessions like, Aluminium froth cooling plate. Aluminium froth on the warming framework for EV battery pack was examined. Supplant of customary folded fin or fluid frosty plate utilized as a part of the battery pack cooling for warming [22]. Battery prognostics and health management (PHM) procedures, with an attention on major neglected needs around there for battery producers, auto designers, and electric vehicle drivers and render practical and savvy answers for managing battery life issues under powerful working conditions. Neuro-fluffy, broadened Kalman channel calculations utilized for encourage applications [23]. The electrochemical portrayal of the novel cathodes and additionally assurance of the particular vitality of simple one-cell batteries containing these novel terminals analysed. The Raman spectra utilized for tube investigation for all intents and purposes [24]. Multifaceted nature regarding its state of charge (SOC) estimation Usage of battery at high temperatures for longer time decreases its life and lessens vehicle execution additionally impacted by the temperature, maturing and charging/releasing cycles. The blunder amongst expected and ascertained estimations of SOC is thought about [25]. The estimation of State of charge (SOC) for control battery packs is noteworthy for hybrid electric vehicle with giving information backings to the effective and fine $\mathrm{EM}$ and exchanging system is confirmed to have great instatement sound qualities and joining practices. Three SOC estimation approaches are led in light of EKF, MMEKF and AFEKF consecutively and the estimation mistakes are inside 8 percent[26].Productivity and sturdiness are getting to be plainly two key issues for the vitality storage framework in electric vehicles together with their related power EMS. Through investigation of the DP control activities under various battery State-of-health (SoH) conditions, close ideal tenets are extricated [27]. The wide dissemination of electric and hybrid vehicles in the market has been restricted as of late by the execution of on-board electric energy storage frameworks. Specifically, electric energy frameworks for automotive applications ought to be portrayed by high power and energy density, long cycle-life, high reliability, wide agent temperature range, low environmental effect. Lithium which have indicated great execution in providing electric vehicles, with high travel range and great dynamic reaction based storage frameworks. The execution and lifetime of these batteries are firmly influenced by their working temperature and operative conditions. Also, the cost of lithium batteries is still high and natural issues identified with lithium metal transfer should be considered. Sodium - nickel chloride batteries: Could be viewed as a fascinating alternative to lithium innovations. Actually, they consolidate lessened cost, high safety and toughness with energy density values, which are comparable with the most widely, recognized lithium advancements. Sodium - nickel chloride batteries, also known with the acronym ZEBRA (Zeolite Battery Research Africa). Are portrayed by a temperature working range of 520-560 $\mathrm{K}$. The high working temperature have really influenced the advancement of ZEBRA batteries for automotive applications, since they introduce self-discharging issues, identified with the need of keeping up high operative temperature notwithstanding when the battery pack isn't providing the electric drive. Huge disadvantage of ZEBRA storage technologies is the low power density values in correlation with the latest lithium innovations, with ensuing low execution as far as vehicle speeding up and charging times [28]. The estimation of state of charge (SOC) for power battery packs is huge for a hybrid electric vehicle with giving information backings to the productive and fine energy managements [29]. Lithium Polymer batteries utilize a solid electrolyte and after that there is no probability of any fluid spillages; moreover they can be made with a thin shape and after that utilized as a part of a more adaptable route, most importantly completing all the more effectively battery packages. Lithium Polymer cells have been subjected to charging/releasing cycles keeping in mind the end goal to examine the voltage trend and the cell performance in various load conditions. One of the issues of Battery Electric vehicles (BEVs) is the low independence in connection to the vehicle usage. While driv- 
ing, slopes or hard increasing speed are given in transit of the vehicle. The power crests, expected of the motor amid the development of the vehicle, are provided from the batteries. The autonomy of the vehicle is lower as much as higher is the battery discharging current in light of the fact that the energy substance of the batteries is discharged in less time [30].Battery frameworks, broadly utilized as vitality stockpiling gadgets for electric vehicles (EVs), experience the ill effects of issues, for example, short lifetimes and low power thickness. In this paper, a hybrid energy storage system (HESS), which is a blend of a supercapacitor (SC) and a battery, that can be charged utilizing WPT innovation, is exhibited .The utilization of such HESSs empowers higher power density of capacity however low energy density must be repaid to additionally diminish size and weight .With adequately visit charging, it is cleared up that ideal energy storage framework can be designed utilizing just a capacitor, and for this situation WPT charge power can be expanded [31].

Lithium batteries: are described by high specific energy, high productivity and long life. These remarkable properties have made lithium batteries the power sources of decision for the consumer electronics market with a generation of the request of billions of units for every year. Electrochemical frameworks, for example, batteries and super capacitors that can productively store and convey energy on request in remain solitary power plants, and give control quality and load levelling of the electrical grid in coordinated frameworks, are assuming a vital part in this field. Lithium ion batteries are light, smaller and work with a voltage of the order of $4 \mathrm{~V}$ with a specific energy running in the vicinity of $100 \mathrm{Whkg}-1$ and $150 \mathrm{Whkg}-1$.Lithium battery technology advances at a pace so fast that assessment of its encouraging may effortlessly end up old. In light of this, we have endeavoured to give some thought to the kind of electrode and electrolyte materials that, in light of their related electrochemistry, morphology and engineering configuration, are relied upon to impact the advance of these vital power sources regarding energy and cycling performance [32].The plan of a close ideal power management strategy for the hybrid battery and ultracapacitor energy storage system (HESS) in PHVs. The arrangement of the HESS utilized as a part of the study is introduced. The battery pack associates with a DC/DC converter in arrangement before it interfaces in parallel with the ultracapacitor pack [33].An undertaking that must be settled for the use of batteries in vehicles with an electric drive train is the assurance of the actual state-of-health $(\mathrm{SOH})$ and state of-charge (SOC) of the battery cells. The fundamental techniques used to gauge SOC are as per the following inside protection strategy, open-circuit voltage strategy, Ampere-Hour counting, neural network and extended Kalman filtering (EKF) [34].

\subsection{Fuel cells}

FCHV control an electric motor and battery by changing over hydrogen gas into power, they start to show up for procurement however offer noteworthy guarantee as a low-carbon clean technology. Hybridization with high specific energy-storage devices, for example, supercapacitors (SCs) has imperative points of interest in Fuel cell (FC) based frameworks. The FCHS is thought to be the most appealing long haul alternative for propulsion of passenger cars. The plan organize incorporates the assurance of the electrical topology and the assurance of the hybridization degree (HD) as per drivability conditions. The point by point model of the FCHS in the Advanced Vehicle test system is talked about. Hybridization with SCs in FC-based vehicles is an important methodology that upgrades execution. The conclusion is that SCs appear the best specialized alternative these days, in light of the fact that FCHVs require storage frameworks with high specific power and high cycle durability. The electrical structure for a FCbased framework basically includes a FC stack with its auxiliary frameworks and the heap, which is for the most part an AC electrical motor. With respect to the lifetime, it is inferred that real batteries are bad for car applications. Be that as it may, a few alterations in the science of traditional lead acid batteries are as of now being produced to work in a high rate incomplete condition of-accuse method of adequate execution [35]. FCs has potential as clean and effective energy hotspots for car applications without forfeit in execution or driving extent. In any case, the entire FC framework must work as productively as conceivable over the scope of driving conditions that might be experienced while keeping up a minimal effort. One advantage that has been driving the improvement of FCs for car applications is the potential for a spotless and effective on-board energy generation with no forfeit in execution or driving scope of the vehicles. UCs demonstrates a beneficial successful braking energy recoup over batteries, which require mechanical braking before electric braking to keep their over-stressing. Indeed, UC are restricted away limit however not in current, so the braking energy recoup can be more total and successful. At long last, batteries experience issues working in cold climate making critical burdens, though UCs can work effectively in wide temperature ranges, stretching out to as low as -40 ${ }^{\circ} \mathrm{C}$. FC-based hybrid frameworks, without a doubt more intricate from a designing perspective. Advantages: Reduced cold start-up time, for the most part in vehicle with on-board reformer, Braking vitality recuperation [36]. Enhancing the performance and creating no discharges Fuel Cells (FCs) speak to an amazing other option to IC engine for controlling vehicles to lighten the developing contamination in urban situations. Simulation and experimentation for a situation ponder relating to a hybrid transport indicate changes on hydrogen utilization and power consistence contrasted with generally announced consumption with equal minimal strategy. Likewise, the correlation with ideal system through Dynamic Programming demonstrates an opportunity to get better to the continuous methodologies [37]. Looking at supercapacitor stage that arranges a difficult compelled powertrain giving bad situation to the EMS as far as efficiency and drivability. Concentrating on concealing this issue, this paper exhibits a novel EMS in view of the estimation of here and now future vitality request and going for keeping up the condition of vitality of the supercapacitor between two cut-off points, which are registered on the web. Correlation with the ideal system through Dynamic Programming demonstrates an opportunity to get better to the ongoing methodologies. EMS for a FCHV in light of the forecast of the vitality request was displayed. The test in this sort of stages is related with the state-subordinate requirements, regularly initiated in operation, which influences sensibly its execution and changes in mileage and drivability contrasted with ECMS [38].The dynamic model of hybrid framework has been built up taking the attributes of motor, ISG engine and grasps into thought. The working methods of the FHEV have been composed in view of the ideal framework and the move plan for the best economy has likewise been proposed. Re-enactment model of the FHEV has been set up on Matlab/Simulink stage. Contrasting and mode progress and moving consecutively, the term of mode change and moving are extraordinarily abbreviated and the rehashed operation of energy sources and actuators are additionally stayed away from. Full HEV furnished with double clutch transmissions has been advanced[39].

\subsection{Flywheel energy}

For a long time flywheels have been utilized to accomplish smoother operation of machines. The older models with absolutely mechanical comprising of just axle connected to a stone wheel. These days are mind boggling developments in which energy is put away mechanically and exchanged to and from the flywheel by a coordinated motor/generator. They are utilized as auxiliary UPS storage in many sectors world over. Future applications traverse a much including EVs, transitional capacity for sustainable power source age and grid usage directly from power quality with drawback a contrasting option to reinforcing transmission. One of the key issues for suitable development is enhancing performance, thus decrease of the overall losses. Amid that time a few shapes and outlines where actualized, however it took until the point that the mid twentieth century. Later in the 1970s flywheel energy 
storage was proposed as an essential goal for EVs and standard power reinforcement. No limit debasement, the lifetime of the flywheel is relatively autonomous of the profundity of the discharge and discharge cycle. It can work similarly well on shallow and on profound releases. Upgrading e.g. battery outline for stack varieties is difficult. No intermittent maintenance is required. One of the significant points of interest of flywheels is the capacity to deal with high power levels. These stores energy in a rotating mass. Depend upon the inactivity and speed of the pivoting mass, a given measure of KE is put away as rotational energy. The flywheel is set inside a vacuum control to dispense with erosion misfortune from the air and suspended by direction for a stabile activity. Active vitality is moved all through the flywheel with an electrical machine that can work either as an engine or generator relying upon the heap point (stage edge). When acting as motor, electric energy provided to the winding of the stator is changed over to torque and connected to the rotor, making it turn quicker and increase KE. In mode of generator KE put away in the torque is applied by rotor, which is changed over to electric energy. The fast rotation of flywheel rotors is reasonable for coordinate of high voltage. Along these lines for flywheel applications, the motor/generator part has an extensive update potential.

\subsection{Solar photovoltaic cells}

In the field solar energy conversion, thin film solar based photovoltaics have been the focal point of innovative work as a promising more practical other option to their silicon counterpart. Late surge of advance in the field of thin film solar cells concentrating on the incorporation of three-dimensional natural- inorganic hybrid perovskites in solar cell devices [40]. It is vital to keep up high productivity while charging electrical energy storage components in order to accomplish all encompassing improvement from an energy generation source (e.g., solar cell array) to an energy storage component (e.g., a supercapacitor bank). Functional arrangement of a sustainable power source orders an electrical energy storage component to remunerate the yield power variance of the inexhaustible source [41].

\subsection{Ultracapacitors}

Supercapacitors have better qualities over batteries as far as cycle efficiency and cycle life. Their cycle efficiency, which is characterized as the proportion of the energy input to the energy yield of an energy storage component, comes to just about $100 \%$. This paper introduces a in an energy management technique electrical hybrid power source (EHPS) for electric vehicular applications. The power sharing relies upon the load power and the condition of charge of the supercapacitors (SC) and the bank of batteries (BAT). The yield voltage remains constantly steady, notwithstanding when a high step load power is forced to the framework [42] In the look for better productivity, auxiliary energy system (AES) for electric vehicles (EVs) was designed, actualized, and tested. "Hybrid" stands for the utilization of at least two energy storage devices that join three principle attributes: specific energy (in watthours per kilogram) for driving extent, specific power (in watts per kilogram) for increasing speed, and power inversion ability for regenerative braking [43]. The test HEV utilizes leadacid batteries, an ultracapacitor (UCAP) bank, and a brushless dc motor with ostensible energy of $32 \mathrm{~kW}$, and peak power of $53 \mathrm{~kW}$. At point when UCAPs were introduced on the vehicle, the expansion in go was around $5.3 \%$ in city tests. Because of its lesserenergy density and specific energy contained in most electric batteries contrasted with that of gas, is settled in hybrid vehicles by joining larger energy density of hydrogen or gas, with high productivity of electric-drive setup [44].

\section{Energy management systems}

The Energy management (EM) calculation of a multi-mode HEV is advanced utilizing Dynamic Programming (DP) considering the mode shift recurrence and energy issue. A mode move present at that point extricated from the working purposes of the DP comes about utilizing the Support vector machine (SVM). By joining the determined mode move delineate the Equivalent consumption minimization system (ECM) in Multi-mode HEV. The mode shift outline procedure of a multi-mode hybrid powertrain is exhibited. Proposed calculation can possibly additionally enhance the efficiency, while keeping up smooth motor operation, and consequently, enhancing the ride comfort of the vehicle [45]. Powertrain arrangement and EMS have been concentrated to enhance the efficiency of the HEV, conquering the confinements of these advancements, lessening energy misfortunes and expanding scope of the vehicle. Model of HEVs is made in a joint effort with some growing firm called I-next [46]. Practical forecast use of HEVs and simulated likewise for the better outcomes. The energy stream framework in powertrain is analysed as Supervisory control framework (SCSs) stage. Execution, EM, powertrain productivity are talked about. Investigated the HEVs powertrain, fuel effectiveness and estimating of the part [47].The ideal control issue was detailed to limit the fuel utilization through managing the power conveyance appropriately between the engine- generator set and battery pack amid a run of the driving time. Possibility of utilizing the Radau pseudospectral method (RPM) to streamline the EMS for a mixture followed vehicle and operational strategies given [48].Various EMSs have been proposed in writing and gives a thorough reference for analysts in the field of HEV advancement, control and enhancement. Parallel, series and mixed hybrid models are explained and furthermore their crises. This point by point examination is gone for featuring the control structure of the surveyed procedures, their oddity, and in addition commitments towards the fulfilment of a few enhancement targets, which incorporates however are not restricted to: lessening of fuel utilization and outflows, charge sustenance, streamlining of braking vitality recovery, and change of vehicle driveability. The equivalent consumption minimisation strategy (ECMS) and model predictive control (MPC) techniques were distinguished for regenerative breaking mechanism advancement [49]. The calculation talked about can be adjusted to different setups of hybrid vehicles and can be utilized to decide ideal controls on any drive cycle for EMS. Ideal issue development and SoC directions are clarified. The calculation given here is capable for EMS advancement[50]. Distinctive HPT control calculations are connected in HV outlines considered followings, limit fuel utilization, limit fumes gas discharge, limit the framework cost, and guarantee great vehicle control qualities. Continuous estimation of financial and environmental qualities for the hybrid 2WD, 4WD.Considering the urban, rough terrain conditions and movement operation [51]. Diverse driving cycles are given MANHATTEN, Hybrid energy storage system (HESS), Assistive power unit (APU) sort for better operation of HEVs. IPM utilized for PHEV vitality framework[52]. Looks at energy unit applications in the cars, more particular to light-operation traveller autos and large transports and military vehicles. Consideration of each sort of hybrids clarified and looked at as needs for that. Vehicle framework and auxiliary storage framework is explained. The vehicle to work in an exceptionally assorted arrangement of modes including all electric operation (series HEV operation, which is used at moderate cruising speeds) accomplished [53].

\section{Future scope and development}

The new proposed integrated Vehicle Hardware In-the-loop (VHiL) and Model Based Design (MBD) approach is used to assess the efficiency of electrified powertrain and a Model-based design is examined (MBD). Rule Based (RB) EMS and Equivalent Consumption Minimization Strategy (ECMS) talked about for 
street utilize. Real fuel productivity of the tested vehicle under various situations. The VHiL is considered as a new advancement for the usage of vehicle test bed as a prescient mechatronic stage for the improvement of vitality productive jolted impetus frameworks and along these lines diminish cost and time. Matlab/Simulink used to analyse two arrangements of information under a few systems [54]. Looks at spatial impacts on hybrid electric vehicle (HEV) appropriation. This is rather than most existing investigations, which focus on dissecting financial variables and socioeconomics. Time arrangement examination is improved the situation unique thought of HEVs and confusion of the HEV managed. Financial development hypothesis, territorial \&labour financial matters Methods utilized for result [55]. Powertrain arrangement and EMS have been concentrated to enhance the efficiency of the HEV, conquering the confinements of these advancements, lessening energy misfortunes and expanding scope of the vehicle. Model of HEVs is made in a joint effort with some growing firm called I-next [56]. Practical forecast use of HEV and simulated likewise for the better outcomes. The energy stream framework in powertrain is analysed as Supervisory control framework (SCSs) stage. Execution, EM, powertrain productivity is talked about. Investigated the HEVs powertrain, fuel effectiveness and estimating of the part. [57]. Investigations HEV merits, the significant procedure unit, the motor and electric engine's mix way. Likewise, it investigations the Series, the parallel and the compound association sort Hybrid electric vehicle's incitation design. Future situation is taken contrasting with Hybrid sorts [58]. Building up driving cycles made out of GPS acquisitions and dividing them into street segments, arranged in various classes relying upon the information parameters, including slant, permits the making of rationale rules characterizing the driving mode to embrace in every circumstance. Utilizing Fuzzy Logic, those principles can be translated and used to adjust the control system to street conditions, bringing about numerous techniques covering each sort of street fragment and offering diverse chances of vitality investment funds. With respect to real ecological and financial risky, enhancing hybrid vehicles constitutes an intriguing arrangement so as to decrease vitality utilizations and gas discharges [59]. To get at the same time a populace of conceivable outline arrangements relating to the most effective vitality framework definition for a vehicle from specialized and monetary perspective. The ideal outlines and working procedures are investigated for various vehicle uses standardized, urban and long way driving. "Tank to wheel balance "technique is conveyed successfully for general upgrade of effectiveness of HEVs. Powertrain plan procedure and versatile driving systems were given [60]. The technique has likewise been tried on an improved rendition of the HVRP as of now displayed in the writing, the Green Vehicle Routing Problem (GVRP), and aggressive outcomes have been gotten. National fuel is significantly more costly than electric drive. The fundamental protest transportation organizations make about electric vehicles utilization is that, given their constrained self-governance, visits to refuelling stations must be arranged along the courses, which infers long deviations from the first way with a resulting increment in voyaged separations and course length [61]. Build up a fitting model for finding most limited routes for these sorts of vehicles, which is for the most part an obliged briefest way issue with convertible resources and charging stations. In (dynamic) movement task issues, one processes client equilibria, where every street client utilizes its individual briefest way and travel time on an edge relies upon the load on this edge [62]. A fault tolerant framework is a sort of framework which it can repair itself when a product or equipment blunder happens, the fundamental point in these frameworks is unwavering quality element which is so essential utilizing repetition strategy (blame tolerant system).Predictive calculation for enhancing dependability include utilizing fluffy rationale, a blame recognition and a blame redress calculation for blame tolerant framework, particular hybrid vehicles talked about [63]. The stability improvement of the engine drives DC input voltage of an electric vehicle with on-board hybrid energy framework. A few focal points in keeping engine drive DC input voltage stable around its ostensible esteem particularly with regards to limit misfortunes and advancement of onboard vitality stockpiling or influence age frameworks with higher particular vitality execution[64]. Contrasts in hybrid and nonhybrid vehicle outline, and potential contrasts in driver-related conduct among themselves, can conceivably have intriguing ramifications for security related arrangements, investigation of roadway damage severities 41-64 AGE cooperation taken into for examination. The numerous physical and behavioural components known to be powerful in deciding damage results recommend that as experts, we won't have the capacity to watch numerous possibly persuasive elements [65]. Study demonstrates the significance of utilizing that power converter to exploit the power qualities of the super-capacitor and to effortlessly actualize on board vitality administration systems to build the entire vehicle execution. Assessments of Performance of a hybrid vitality storage system to supply urban electric vehicles for Indian situation and MatlabSimulink re-enactment demonstrate for EM technique [66]. EM approach for HV is proposed, which improves the vehicle speed profile while limiting the fuel utilization with the assistance of the activity review data, so a further vitality putting something aside for HV can be accomplished. In all actuality, nonetheless, the driving cycle isn't settled, and it is subject to the activity condition and the driver's conduct. Subsequently, EM procedures joined by the expectation without bounds driving cycle were created for hybrid vehicles, the power allotment enhancement is without a doubt vital. Furthermore, the power allotment streamlining ought to be joined with the driving course enhancement for HV so as to additionally enhance the efficiency [67]. Deals with the issue of vitality EM in hybrid electric vehicles, considering conceivable answers for tending to the power split, all things considered, conditions. Examination between two on-line vitality EM methodologies for hybrid vehicles, the Stochastic Dynamic Programming (DP) and the Equivalent consumption Minimization Strategy [68]. Different sorts of TM framework have been utilized as a part of the electric vehicle's battery pack, for example, air cooling, fluid cooling and stage change material to keep the temperature inside ideal range by utilizing CFD Simulation. Permeable aluminium used to keep up to keep up the warm property rather than carbon use [69]. The electrochemical portrayal of the novel cathodes and additionally assurance of the particular vitality of simple one-cell batteries containing these novel terminals analysed. The Raman spectra utilized for tube investigation for all intents and purposes [70]. The innovative advancements, two specific angles are featured here, (a) the power splitting or power consolidating transmission regularly in view of a blend of mechanical and electrical segments and (b) the supervisory control system for dealing with the power streams to acquire both high effectiveness and great driveability. Patterns in control part transmissions have been compressed and ways to deal with planning appropriate controllers have been broke down [71]. To meet the prerequisites to the driveability, the position control of the hydraulic powered clutch actuator is vital, since the transmitted clutch torque relies upon the position of the clutch actuator. Feedforward control is updated with an adaption to consider the temperature reliance of the trademark stream bend. The control of the hydraulic clutch actuator is essential to give great drivability [72]. The fuel utilization benefits which can be acknowledged while using HEV design are subject to what amount braking vitality is recovered, and how well the recovered vitality is used, here part of parallel HEV demonstrating, control and improvement considered. Rule- based (RB) control systems and Dynamic programming utilized for charge supporting and driving modes [73]. Flow library has been produced as a business Modelica library to help the assessment of the numerous innovation and topology alternatives, highlights of the library that are utilized as a part of the simulation of vehicle transients, for example, starting dispatch, tip-in and tip-out and gear moving. A powertrain under unique conditions both over a short time span (high determination) and quick transients talked about [74]. 


\section{Conclusion}

Through analysing feature of every parts in Hybrid vehicle, the Energy Management System(EMS) ,Rule based operation, battery strategy, drivability, operation of HV in vital terrains, cost estimation, urban usage and its efficiency impacts ,types of hybrids for different aspects like Series, Parallel and Combined hybrids are elaborated with their application in multi-level. Feature hybrids called Plug-in hybrids are taken into for further research with the charging point installation for Indian scenario.

\section{References}

[1] M. Awadallah, P. Tawadros, P. Walker, and N. Zhang, "Dynamic modelling and simulation of a manual transmission based mild hybrid vehicle," Mech. Mach. Theory, vol. 112, pp. 218-239, 2017. https://doi.org/10.1016/j.mechmachtheory.2017.02.011

[2] S. G. Wirasingha, S. Member, A. Emadi, and S. Member, "Pihef: Plug-In Hybrid Electric Factor,” vol. 60, no. 3, pp. 1279-1284, 2011.

[3] L. Ju, Z. Tan, H. Li, X. Yu, and H. Zhang, "Model for Wind Power and Plug-In Hybrid Electric Vehicles under Different GridConnected Modes," vol. 2014, 2014

[4] M. Ikram, M. Rashid, and H. Danial, "ADVISOR Simulation and Performance Test of Split Plug-in Hybrid Electric Vehicle Conversion," Energy Procedia, vol. 0, pp. 1-6, 2016.

[5] F. Millo, C. Cubito, L. Rolando, E. Pautasso, and E. Servetto, "Design and development of an hybrid light commercial vehicle," Energy, pp. 1-10, 2015.

[6] X. Wang, H. He, F. Sun, X. Sun, and H. Tang, "Comparative study on different energy management strategies for plug-in hybrid electric vehicles," Energies, vol. 6, no. 11, pp. 5656-5675, 2013 https://doi.org/10.3390/en6115656.

[7] Modelling of electric and parallel-hybrid electric vehicle using Matlab/Simulink environment and planning of charging stations through ageographic information system and genetic algorithms Susana Alegre $\square$, Juan V. Míguez, José Carpio

[8] A. Al-Samari, "Study of emissions and fuel economy for paralle hybrid versus conventional vehicles on real world and standard driving cycles," Alexandria Eng. J., pp. 1-6, 2016.

[9] S. Alegre, J. V. Míguez, and J. Carpio, "Modelling of electric and parallel-hybrid electric vehicle using Matlab/Simulink environment and planning of charging stations through a geographic information system and genetic algorithms," Renew. Sustain. Energy Rev., vol. 74, no. February, pp. 1020-1027, 2017. https://doi.org/10.1016/j.rser.2017.03.041.

[10] Study of emissions and fuel economy for parallel hybrid versus conventional vehicles on real world and standard driving cycles Ahmed Al-Samari

[11] P. M. J. Kamper, "Hybrid Electrical Vehicles," no. June, 2008.

[12] Stability enhancement of the motor drive DC input voltage of an electric vehicle using on-board hybrid energy storage systems João P. Trovãoa,b, $\square$, Mário A. Silvab, Carlos Henggeler Antunesb,c, Maxime R. Duboisa

[13] P. Piliay, "Literature survey of permanent magnet ac motors and drives p. piliay, member, ieee, and," 1989.

[14] H. Performance, "Advanced BLDC Motor Drive for Low Cost and High Performance Propulsion System in Electric and," pp. 246-251, 2001 .

[15] D. M. Bellur and M. K. Kazimierczuk, "DC-DC CONVERTERS FOR ELECTRIC VEHICLE APPLICATIQNS,” pp. 286-293, 2007.

[16] I. Boldea et al., "With Reduced or No Permanent Magnets : An Overview," vol. 61, no. 10, pp. 5696-5711, 2014.

[17] C. Namuduri and P. C. Sen, "A Servo-Control System Using a SelfControlled Lt-," vol. I, no. 2, pp. 283-295, 1987.

[18] S. Nikam, R. Vandana, and B. G. Fernandes, "A high torque density permanent magnet free motor for in-wheel electric vehicle application," no. c, 2011

[19] P. C. Sen, "Electric Motor Drives and Control-Past, Present , and Future," vol. 37, no. 6, pp. 562-575, 1990

[20] J. P. Trovão, M. A. Silva, C. Henggeler, and M. R. Dubois, "Stability enhancement of the motor drive DC input voltage of an electric vehicle using on-board hybrid energy storage systems,' Appl. Energy, vol. 205, no. March, pp. 244-259, 2017. https://doi.org/10.1016/j.apenergy.2017.07.084.
[21] K. P. Phillips, "Current-Source Converter for," vol. I, no. 6, pp $679-683,1972$

[22] L. Huat, Y. Ye, M. Chian, W. Tong, M. Kun, and T. Ching, "Computational fluid dynamics simulation on open cell aluminium foams for Li-ion battery cooling system," Appl. Energy, 2017.

[23] S. M. Rezvanizaniani, Z. Liu, Y. Chen, and J. Lee, "Review and recent advances in battery health monitoring and prognostics technologies for electric vehicle (EV) safety and mobility," $J$.

[24] R. S. Morris, B. G. Dixon, T. Gennett, R. Raffaelle, and M. J Heben, "High-energy , rechargeable Li-ion battery based on carbon nanotube technology ๕a,” vol. 138, pp. 277-280, 2004.

[25] A. Panday and H. O. Bansal, "Hybrid Electric Vehicle Performance Analysis under Various Temperature Conditions," Energy Procedia vol. 75, pp. 1962-1967,

2015 https://doi.org/10.1016/j.egypro.2015.07.238.

[26] S. Xie, R. Xiong, Y. Zhang, and H. He, "The Estimation of State of Charge for Power Battery Packs used in Hybrid Electric Vehicle," Energy Procedia, vol. 105, no. 10, pp. 2678-2683, 2017. https://doi.org/10.1016/j.egypro.2017.03.774.

[27] S. Zhang, R. Xiong, and J. Cao, "Battery durability and longevity based power management for plug-in hybrid electric vehicle with hybrid energy storage system," Appl. Energy, vol. 179, pp. 316328, 2016. https://doi.org/10.1016/j.apenergy.2016.06.153.

[28] C. Capasso and O. Veneri, "Integration between Super-capacitors and ZEBRA Batteries as High Performance Hybrid Storage System for Electric Vehicles," Energy Procedia, vol. 105, pp. 2539-2544, 2017. https://doi.org/10.1016/j.egypro.2017.03.727.

[29] The Estimation of State of Charge for Power Battery Packs used in Hybrid Electric Vehicle Shanshan Xiea,b, Rui Xionga,b, Yongzhi Zhanga,b, Hongwen Hea,b, *

[30] C. Pinto, J. V Barreras, R. De Castro, R. E. Araújo, and E. Schaltz, “AC," Energy, 2017.

[31] T. Hiramatsu, X. Huang, M. Kato, and Y. Hori, "Capacity Design of Supercapacitor-Battery Hybrid Energy System with Repetitive Charging," vol. 197, no. 3, pp. 898-905, 2016.

[32] A. Khaligh, S. Member, Z. Li, and S. Member, "Battery , Ultracapacitor, Fuel Cell, and Hybrid Energy Storage Systems for Electric , Hybrid Electric, Fuel Cell , and Plug-In Hybrid Electric Vehicles: State of the Art," vol. 59, no. 6, pp. 2806-2814, 2010 https://doi.org/10.1109/TVT.2010.2047877.

[33] Battery durability and longevity based power management for plugin hybrid electric vehicle with hybrid energy storage system Shuo Zhang a, Rui Xiong a,b, , Jiayi Cao a

[34] X. Zhao and L. Yang, "IMECE 2012-87324 a strategy for estimating state-of-charge and state-of-health of li-ion batteries in electric and hybrid electric vehicles," pp. 1-8, 2016.

[35] Energy management strategy for fuel cell-supercapacitor hybrid vehicles based on prediction of energy demand Mauro G. Carignano a, *, Ramon Costa-Castello b, Vicente Roda c, Norberto M. Nigro d, Sergio Junco e, Diego Feroldi

[36] D. Feroldi, M. Serra, and J. Riera, "Design and Analysis of FuelCell Hybrid Systems Oriented to Automotive Applications," vol. 58, no. 9, pp. 4720-4729, 2009.

[37] G. Pede, A. Iacobazzi, S. Passerini, A. Bobbio, and G. Botto, "FC vehicle hybridisation: an affordable solution for an energy-efficient FC powered drive train," vol. 125, pp. 280-291, 2004.

[38] M. G. Carignano, R. Costa-Castelló, V. Roda, N. M. Nigro, S Junco, and D. Feroldi, "Energy management strategy for fuel cellsupercapacitor hybrid vehicles based on prediction of energy demand," J. Power Sources, vol. 360, pp. 419-433, 2017. https://doi.org/10.1016/j.jpowsour.2017.06.016

[39] Z. Lei et al., "Analysis and coordinated control of mode transition and shifting for a full hybrid electric vehicle based on dual clutch transmissions," Mech. Mach. Theory, vol. 114, pp. 125-140, 2017 https://doi.org/10.1016/i.mechmachtheory.2017.04.001

[40] A. Dualeh, N. Tétreault, T. Moehl, and P. Gao, "Effect of Annealing Temperature on Film Morphology of Organic Inorganic Hybrid Pervoskite Solid-State Solar Cells," pp. 1-9, 2014 https://doi.org/10.1002/adfm.201304022.

[41] Y. Kim, N. Chang, Y. Wang, and M. Pedram, "Maximum Power Transfer Tracking for a Photovoltaic-Supercapacitor Energy System *," 2010 https://doi.org/10.1145/1840845.1840909.

[42] Ultracapacitors for Use in Power Quality and Distributed Resource Applications Philip P. Barker - IEEE Senior Member

[43] Ultracapacitor technologies and application in hybrid and electric vehicles Andrew Burke,y

[44] Energy Management of a Fuel Cell/Supercapacitor/Battery Power Source for Electric Vehicular Applications Majid Zandi, Alireza 
Payman, Jean-Philippe Martin, Serge Pierfederici, Bernard Davat, Member, IEEE, and Farid Meibody-Tabar

[45] M. Ortúzar, J. Moreno, J. Dixon, and S. Member, "Implementation and Evaluation of an Ultracapacitor Based Auxiliary Energy System for Electric Vehicles," vol. 54, no. 4, pp. 2147-2156, 2007.

[46] W. Zhuang, X. Zhang, D. Li, L. Wang, and G. Yin, "Mode shift map design and integrated energy management control of a multimode hybrid electric vehicle," Appl. Energy, vol. 204, pp. 476-488, 2017 https://doi.org/10.1016/j.apenergy.2017.07.059.

[47] S. A. Evangelou and W. Shabbir, "Dynamic modeling platform for series hybrid electric vehicles," IFAC-PapersOnLine, vol. 49, no. 11, pp. 533-540, 2016. https://doi.org/10.1016/j.ifacol.2016.08.078.

[48] S. Wei, Y. Zou, F. Sun, and O. Christopher, "A pseudospectral method for solving optimal control problem of a hybrid tracked vehicle," Appl. Energy, vol. 194, pp. 588-595, 2017 https://doi.org/10.1016/j.apenergy.2016.07.020.

[49] W. Enang and C. Bannister, "Modelling and control of hybrid electric vehicles (A comprehensive review)," Renew. Sustain. Energy Rev., vol. 74, no. January, pp. 1210-1239, 2017. https://doi.org/10.1016/j.rser.2017.01.075.

[50] M. Schori, T. J. Boehme, B. Frank, and M. Schultalbers, Solution of a Hybrid Optimal Control Problem For a Parallel Hybrid Vehicle, vol. 46, no. 21. IFAC, 2013.

[51] L. Raslavičius, A. Keršys, and R. Makaras, "Management of hybrid powertrain dynamics and energy consumption for $2 \mathrm{WD}, 4 \mathrm{WD}$, and HMMWV vehicles," Renew. Sustain. Energy Rev., vol. 68, no. September 2016, pp. 380-396, 2017.

[52] S. Zhang, R. Xiong, and F. Sun, "Model predictive control for power management in a plug-in hybrid electric vehicle with a hybrid energy storage system," Appl. Energy, vol. 185, pp. 1654 1662, 2017 https://doi.org/10.1016/j.apenergy.2015.12.035.

[53] A. Emadi, K. Rajashekara, S. S. Williamson, and S. M. Lukic "Topological overview of hybrid electric and fuel cell vehicular power system architectures and configurations," IEEE Trans. Veh. Technol., vol. 54, no. 3, pp. 763-770, 2005 https://doi.org/10.1109/TVT.2005.847445.

[54] Ra, S. Kumar, P. Pisu, J. Rios, and P. Jethani, "Model-based design validation for advanced energy management strategies for electrified hybrid power trains using innovative vehicle hardware in the loop ( VHIL ) approach," Appl. Energy, vol. 204, pp. 287-302, 2017 https://doi.org/10.1016/j.apenergy.2017.07.028.

[55] X. Liu, M. C. Roberts, and R. Sioshansi, "Spatial effects on hybrid electric vehicle adoption," Transp. Res. Part D Transp. Environ., vol. 52, pp. 85-97, 2017. https://doi.org/10.1016/j.trd.2017.02.014.

[56] Napoli, F. Sergi, and V. Antonucci, "Study and design of a hybrid electric vehicle (Lithium Batteries-PEM FC)," Int. J. Hydrogen Energy, vol. 42, no. 5, pp. 3166-3184, 2017. https://doi.org/10.1016/j.ijhydene.2016.12.082.

[57] S. A. Evangelou and W. Shabbir, "Dynamic modeling platform for series hybrid electric vehicles," IFAC-PapersOnLine, vol. 49, no. 11, pp. 533-540, 2016. https://doi.org/10.1016/j.ifacol.2016.08.078.

[58] H. Li and G. Zhang, "Hybrid electric vehicle drive control," Procedia Environ. Sci., vol. 10, no. PART A, pp. 403-407, 2011.

[59] S. Brouk, M. Buey, S. Ly, M. Pedron, and S. Burgalat, "Control strategies for hybrid vehicles in mountainous areas," Procedia Comput. Sci., vol. 60, no. 1, pp. 284-291, s2015.

[60] Z. Dimitrova and F. Maréchal, "Techno-economic design of hybrid electric vehicles using multi objective optimization techniques," Energy, vol. 91, pp. 630-644, 2015. https://doi.org/10.1016/j.energy.2015.08.073.

[61] S. Mancini, "The Hybrid Vehicle Routing Problem," Transp. Res. Part C Emerg. Technol., vol. 78, pp. 1-12, 2017. https://doi.org/10.1016/j.trc.2017.02.004.

[62] M. Strehler, S. Merting, and C. Schwan, "Energy-efficient shortest routes for electric and hybrid vehicles," Transp. Res. Part B Methodol., vol. 0, pp. 1-25, 2016.

[63] F. Mirhakimi and A. Karimi, "A preliminary study for improving reliability in hybrid vehicles," Procedia Comput. Sci., vol. 42, no. C, pp. 308-312, 2014. https://doi.org/10.1016/j.procs.2014.11.067.

[64] J. P. Trovão, M. A. Silva, C. Henggeler, and M. R. Dubois, "Stability enhancement of the motor drive DC input voltage of an electric vehicle using on-board hybrid energy storage systems," Appl. Energy, vol. 205, no. March, pp. 244-259, 2017. https://doi.org/10.1016/j.apenergy.2017.07.084

[65] P. Seraneeprakarn, S. Huang, V. Shankar, F. Mannering, N. Venkataraman, and J. Milton, "Occupant injury severities in hybrid-vehicle involved crashes: A random parameters approach with heterogeneity in means and variances," Anal. Methods Accid. Res., vol. 15, pp. 41-55, 2017. https://doi.org/10.1016/j.amar.2017.05.003.
[66] C. Capasso and O. Veneri, "Integration between Super-capacitors and ZEBRA Batteries as High Performance Hybrid Storage System for Electric Vehicles," Energy Procedia, vol. 105, pp. 2539-2544, 2017. https://doi.org/10.1016/j.egypro.2017.03.727.

[67] C. Zheng, G. Xu, K. Xu, Z. Pan, and Q. Liang, "An energy management approach of hybrid vehicles using traffic preview information for energy saving," Energy Convers. Manag., vol. 105, pp. 462-470, 2015 https://doi.org/10.1016/j.enconman.2015.07.061

[68] D. B. T. Leroy, Impact of Driveability Constraints on Local Optimal Energy Management Strategies for Hybrid Powertrains, vol. 46, no. 21. IFAC, 2013.

[69] L. Huat, M. Chian, M. Kun, and W. Tong, "Numerical analyses on aluminum foams cooling plate for lithium-ion batteries," Energy Procedia, vol. 105, pp. 4751-4756, 2017. https://doi.org/10.1016/j.egypro.2017.03.1034.

[70] R. S. Morris, B. G. Dixon, T. Gennett, R. Raffaelle, and M. J. Heben, "High-energy , rechargeable Li-ion battery based on carbon nanotube technology 气,” vol. 138, pp. 277-280, 2004

[71] Q. Ren, D. A. Crolla, and A. Wheatley, "Power management and control strategies for a hybrid vehicle with a," 2006

[72] R. Gasper, M. G. Chavez, and D. Abel, "Adaptive flatness based control of a hydraulic clutch actuator," IFAC Proc. Vol., pp. 707 712, 2010. https://doi.org/10.3182/20100901-3-IT-2016.00070.

[73] W. Enang and C. Bannister, "Modelling and control of hybrid electric vehicles ( A comprehensive review )," Renew. Sustain. Energy Rev., vol. 74, no. August 2016, pp. 1210-1239, 2017.

[74] N. Roberts, M. Dempsey, and A. Picarelli, Detailed Powertrain Dynamics Modelling in Dymola - Modelica, vol. 46, no. 21. IFAC, 2013. 